\title{
Planning and Scheduling of Underground Metro Station Box Using MSP Software
}

\author{
Ankur Marathe ${ }^{1}, S_{\text {Salil Nibandhe }}^{2}$, Lloyd Moraes ${ }^{3}$,Vedang Save ${ }^{4}$, Prof. Shreeshail B Heggond \\ ${ }^{1,2,3,4}$ (UG Students), ${ }^{5}$ Assistant Professor, Department of Civil Engineering, St John College of Engineering \& \\ Management, Palghar
}

DOI: 10.46335/IJIES.2020.5.6.4

\begin{abstract}
The infrastructure development in Mumbai city is carried out on a large scale in recent times. The Mumbai Metro project is one such project which is recently under construction and one-of-its kind project. In our project we have mainly worked on the Construction Management of the metro project which involves Line 3 of the metro project. The scheduling of various activities has been done in the Microsoft Project Management Software by adding various activities, subactivities, duration, resources required and cost of each resource. The various difficulties and the challenges faced during the entire project were also identified and various practical solutions were also given regarding the same. As the project is under construction, various delays caused during the project were also identified. The rapid transit system of Mumbai Metro is a solution to the large amount of traffic and accidents occurring in the city. It is being built with an estimated cost of Rs.30000crores with overall completion expected in year 2021. When completed, the core system will comprise of 27 stations with line length 33.5kms for the line ColabaBandra-Seepz.
\end{abstract}

Keywords- construction management, Mumbai metro, project management software, rapid transit system, scheduling

\section{I- INTRODUCTION}

\section{Line 3 (Mumbai Metro)}

T he Aqua Line of the Mumbai Metro also known as Line $\mathbf{3}$ or the Colaba-Bandra-SEEPZ line, is a part of the metro system for the city of Mumbai, India of which construction has been initiated. When completed, the $33.5-\mathrm{km}$ long line will be the first underground metro line in Mumbai. The metro line will connect Cuffe Parade business district in the extreme south of the city to SEEPZ in the north-central with 26 underground and one at-grade station. The track width is standard gauge. The cost of this corridor is estimated at Rs.30000 crore (US\$4.3 billion). Line 3 is expected to reduce road congestion, besides reducing the load on the Western Line between Bandra and Churchgate.The project is being implemented by the Mumbai Metro Rail Corporation Limited (MMRCL). The line starts at Cuffe Parade, will run through Nariman Point , Churchgate, CSMT, Girgaon, Worli, Dadar, Mahim, Ban dra-Kurla Complex, Santacruz (East) and past the domestic and international terminals of Mumbai Airport, through Andheri MIDC and terminates at SEEPZ. The section of the line between Bandra Kurla Complex and Dharavi stations includes a 170 metre long tunnel passing under the Mithi river. This will be the second under-river metro rail tunnel in India after the tunnel underneath the Hooghly river on Kolkata Metro Line 2 .The $33.5 \mathrm{~km}$, Rs. 23,136 crore project involves five major entities - MMRCL (Mumbai Metro Rail Corporation Limited), Padeco, MMRDA, CREC (China).Major (65\%) funding for the project was received through a soft loan of Rs. 13,235 crore from JICA (Japan International Cooperation Agency) with the rest provided by the exchequer through the Government of India and Government of Maharashtra.

\section{II- METHODOLOGY}

The methodology of the project involves:

- Determination of objective and scope of study. 
- Critical literature review.

- Detailed study of total project management.

- Understanding of MS Project Software.

- Conducting Site Visits.

- Data collection and data analysis.

- Implementation of MS Project Software.

- Conclusion.

- Documentation of study.

\section{III- MSP SOFTWARE}

- Microsoft Project is a project management software product, developed and sold by Microsoft. It is designed to assist a project manager in developing a schedule, assigning resources to tasks, tracking progress, managing the budget, and analyzing workloads.

- The scheduling of the entire project has been done in the MSP software.

- All the activities, sub-activities, duration, resources, cost all have been added in the software.

- Some of the problems faced during the project were also identified and their solutions were discussed.

The delays occurred due to these problems have also been incorporated in the software.

Three types of resources are supported on Microsoft software:

- Work resources which contain material and labour to complete the activity.

- Cost resources which exhibit a financial cost.

- Material resources contain the materials consumed during the project.

The project summary is as follows:

- Start date of project:06/02/2020

- $\quad$ End date of project: 25/06/2021

- Total duration of project:476

- Total cost of the project: Rs.17,196,791,321.90

- Total main activities added:25

- Total activities (including sub-activities): 279
All the activities which were added in the software along with their resources, duration and cost of each item.

The images below indicate the main activities and their corresponding Gantt Charts obtained:

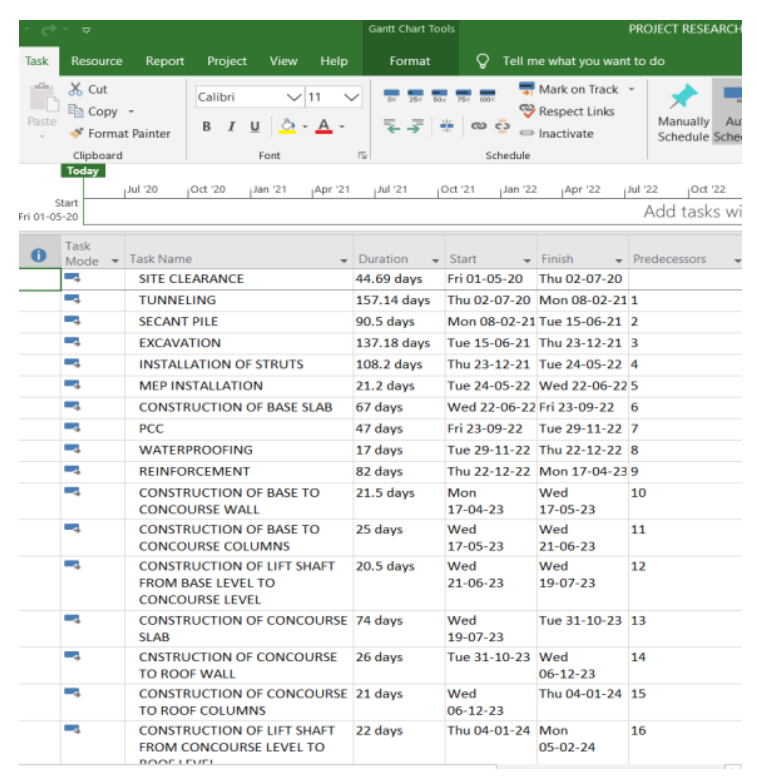

Fig 1- Activities

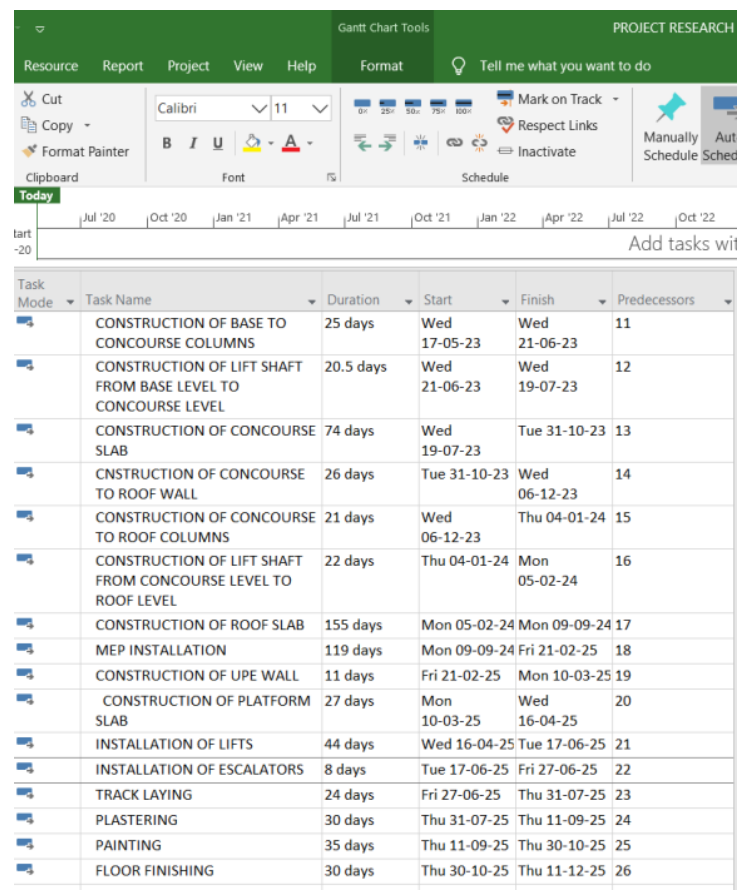

Fig 2- Activities continued 


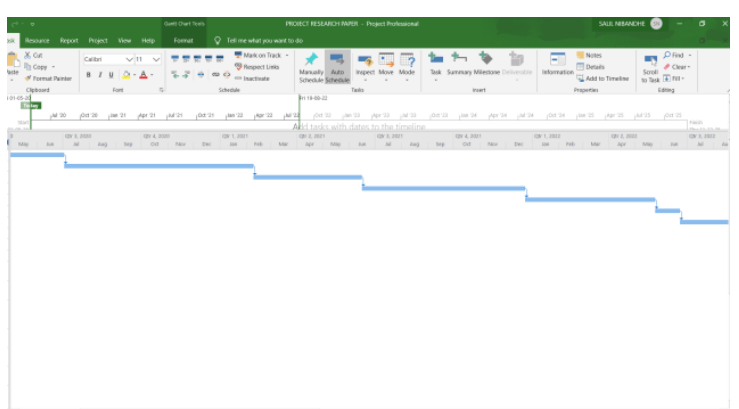

Fig 3- Gantt Chart 1

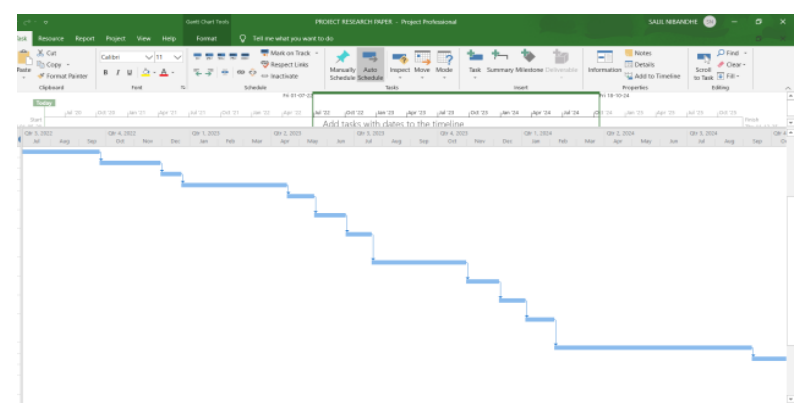

Fig 4- Gantt chart 2

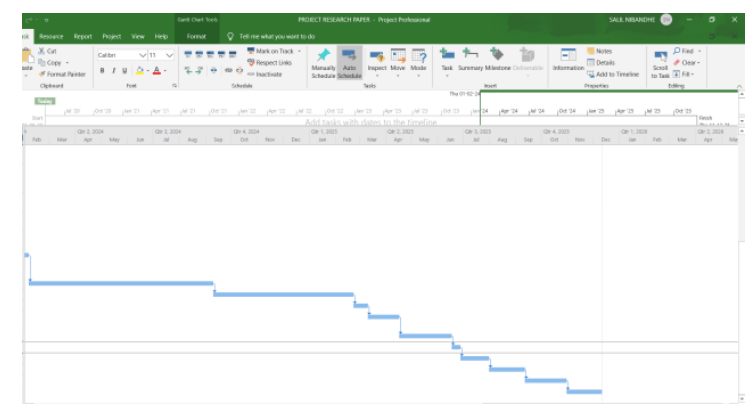

Fig 5- Gantt chart 3

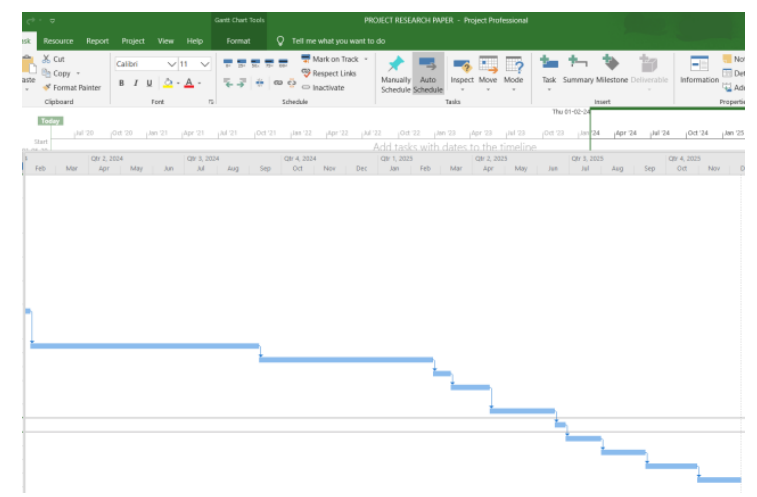

Fig 6- Gantt chart 4

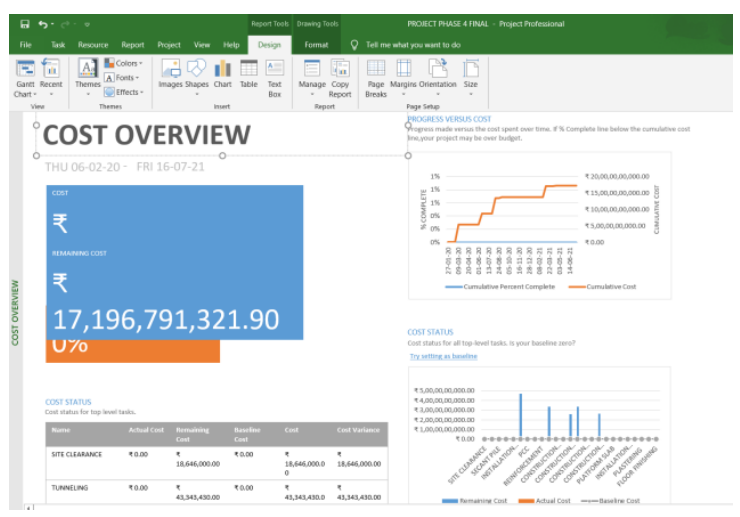

Fig 7- Cost Overview

\section{IV- DIFFICULTIES / CHALLENGES FACED AND SOLUTIONS}

- Due to the traffic load at grade, the concreting work could not be carried out at the daytime. Hence most of the concreting work was carried out at the night time.

- During the process of construction most of the underground water pipelines, sewer pipelines, drainage pipelines were overcome. The construction work was carried out keeping the pipelines safe.

- The variation in climatic conditions also played a major factor during the construction process.

- Various new type of construction practices like the scissor type of construction were practiced.

- Various other difficulties such as river overflow, occurrence of big rocks, removal of water from excavated pit were also successfully solved.

\section{V- $\quad$ RESULTS}

- After the various activities were added in the software, the GANTT CHART was obtained.

- The interdependencies amongst various activities are shown in the Gantt chart.

- Also the total approximate cost incurred for the project is also shown in the software.

- The critical path activities along with the flowchart are depicted in the result section of the software.

- The challenges faced during the project and the effect of those challenges on the activities and thereon on the project are studied. 


\section{VI- FUTURE SCOPE}

- $\quad$ The ongoing Underground Mumbai Metro 3 project of total 27 stations in which 26 stations underground and one station at grade is expected to be completed by the year 2021 .

- This project will reduce road traffic congestion in the city massively which is the prime cause and concern of this project.

- Efficient planning and scheduling of such mass infra projects will help in the completion of the project within time and budget both.

- In future for management of any mass infra project, Efficient use of management software like MSP will help in proper planning and scheduling of the activities along with the duration and budget of the project. It will reduce the efforts of management and will help in solving the problems and corrections within no time.

- This concept of underground construction is adopted in many cities abroad, and when the question of traffic congestion arises, going underground is the best way possible and very definitely this concept will be adopted in future wherever in need.

\section{VII- CONCLUSIONS}

- In the course of the project we were able to gain knowledge of ongoing activities by visiting on site of CSMIA T2 Station and the procedure of construction activities were obtained and studied with respect to TIME, MATERIAL AND COST. Accordingly further those activities were put in MSP software along with duration and cost. (Cost of the resources was obtained from DSR of Mumbai and Delhi.)

- On the basis of assumptions of the future challenges or difficulties, corrective actions were shown in the software like lagging of activities due to various factors affecting, scissor crossing of tracks taking place affecting in delay of tunneling work, delay in excavation activity due to hydraulic excavator breakdown, delay in joining the two packages after tunnel breakthrough etc.

- Accurate and efficient planning and scheduling was done on MSP software. MSP software made easy working and better results with quick improvisation of corrections and solving problems.

- When the activities were added in the software, we could understand the different areas of MSP software to gain in depth knowledge of software.

- Overall the entire project work was very informative and we gathered much more information about the ongoing project and understood various factors which play vital role in such type of mass infra projects or rapid transit system projects.

\section{REFERENCES}

[1] Mumbai Mahanagar Region Development Authority [M.M.R.D.A.]letterno.09date.12/01/2015Updated Environmental Impact Assessment Report Mumbai metro project phase 3.pdf http:// https://www.mmrcl.com/

[2] Detailed project report - Mumbai metro line 3 Colaba-Bandra-Seepz (533 pages) (PDF). Mumbai Mumbai metro rail corporation limited / RITES (GOI).http:// https://www.mmrcl.com/ 1 November 2011Retrieved 27 August 2018.

[3] Author-PurvaChitnis Mumbai Metro-3 Likely To Be Completed By

December https://www.bloombergquint.com/business/mumbaimetro-3-likely-to-be-completed-by-december-2021 date 14 October 2017

[4] Author-Manthan. K. Mehata Metro company to be revamped for Colaba-SE.. Site-https://t imesofindia. indiatimes.com /city/mumbai/Metro-company-to-be-revamped-forColaba-SEEPZ-route/articleshow/29128447.cms Date 21 January 2014

[5] Reporter, B. S. (8 December 2014). "AECOM Asia appointed as general consultant for Mumbai Metro III project". Business Standard India - via Business Standard.

[6]"Mumbai Metro Rail Corporation ". MMRDA.MMRDA. Establishment of MMRC: As per State Govt. directives Mumbai Metro Rail Corporation (MMRC) has been constituted as fully owned company of MMRDA (registered under provisions of Company Act, 1956) as of 30th April, 2008. MMRC (at present) is responsible for the implementation of all the Metro Rail Corridors under Mumbai Metro Rail Project.Archived from the original on 2 November 2013.Retrieved 4 March 2014.

[7] Pillay, Amritha (6 March 2019). "Mumbai Metro line 3 project estimated to cost Rs 7,000 crore 
International Journal of Innovations in Engineering and Science, Vol 5, No.6, 2020

\section{$w w w . i j i e s . n e t$}

more". Business Standard India. Retrieved 14 March 2019.

[8] Author - MMRCL contact Contracts awarded for Mumbai Metro Line 3 construction works". The Global Rail Alliance. Retrieved 10 February 2017

[9] Author - Swapnil Rawal "Seven firms bid to design and supply Mumbai Metro-3 coaches". Sitehttp://www.hindustantimes .com. 22 June 2017. Retrieved 5 July 2017 